\title{
Overswaying Inner-conflicts Matters in Organizational Settings: Categories, Impacts, Necessities and Strategies of Well-managed Conflicts
}

\author{
Li Bo, Lina Vyas \\ Lingnan University, Hong Kong, China, 999077 \\ The Education University of Hong Kong, China, Hong Kong, 999077
}

Keywords: conflicts Matters, Necessities, Strategie

\begin{abstract}
Conflicts are everywhere in diverse organizational settings which could be influenced a lot by how organizations response to conflicts existing in the process of administration. Productive work outcomes and high efficient employees are one of results of well-managed conflicts, which can starkly reflect whether organizations are capable to handle conflicts well. As to the mentioned above, conflict is a double-edged sword that could harm the benefits of organizations, at same time it probably bring about satisfactions for all of stakeholders in organizations as long as organizations figure out the proper methods. Based on the two-dimensional taxonomy, organizations should consider how to adapt strategies to manage conflicts in order to get to ultimate organizational targets. In addition, crucially, training a quality administrative team plays a tremendously crucial role in pursuing perfection of managing conflicts and of business operation as well as of organizational values.
\end{abstract}

\section{Introduction}

Currently, many of diverse types of organizations commence constantly on managing work conflicts that frequently appear in any kinds of administrative processes including discussions, decision-makings and operations. This essay referring to previous studies sheds light on the viewpoint of how our learning group thinks of impacts of conflicts in organizational settings. In other words, rarely do people think of that work conflicts can make a tremendous difference in producing innovative ideas and good outcomes eventually, yet the standpoint of this essay is that it is applicable to organization successes, which especially likely happens to comparatively democratic organizations where participants can express ideas without worries about troubles due to contradictory voices coming out. In other words, the idea put in this paper primarily is that managing conflict in proper approaches should be one of useful drivers that can push work groups to create more possibilities and spaces for exchanging ideas and deepening understandings. Organizations do not necessarily need to take much time to consider how to avoid conflicts coming out within organizations. Yet, one thing, crucially, that needs to be deliberate and even handled carefully by organizations is to manage conflicts in proper ways.

Of the structure, primarily, this essay consists of four dimensions, namely what specific work conflicts appear in organizations, how work conflicts impact organizations and why organizations need to manage conflicts as well as how organizations handle intricate conflicts. Emphatically, conflicts may emerge in both interior (or within organizations) and exterior (or external organizations). This essay mainly discourses conflicts within organizations, which is also named well-known as inter-group conflicts.

\section{Conflicts in Organizational Settings}

According to the theory of conflict management, conflicts within organizations can generally be classified as five different dimensions: interpersonal conflicts, individual-group conflicts, superiorsubordinate conflicts, superior-group conflicts and group conflicts. All kinds of conflicts within organizations are grew out of these five types of conflicts. 
Undoubtedly, more organizational teams have realized gradually that many issues they confront and try to figure out require organizations that are able to handle conflicts for successful targets (Neck \& Manz, 1994; Sims, 1995), which is, indeed, one of necessary parts in whole process of management to probably produce positive results. In terms of its importance and potential influences to organizations, the increasing number of literatures start to focus on conflict management with critical thinking.

Based on the statement by Myers and Larson (2005), work conflicts can be relational, process and task oriented. In any types of organizations, conflicts exist in each step of day-to-day administrations. For example, one of coworkers rejects ideas you put forward in a specific project, which may lead to the interpersonal conflict among colleagues. Further, employees fail to up to scratch and expectations of supervisors due to any kinds of possible reasons, which could bring about conflicts between managers and subordinators, which is called as the superior-subordinate conflict. Some researchers and investigators also proposed relevant ideas regarding the explanation of conflicts, Tjosvold (2008) states that conflict can be labelled as an effective process of administration which could be constructive, indeed, essential to teamwork. In his study, conflicts are not regarded as a confounding variable harming outcomes but a tool of benefitting organizations so long as it is managed well. This idea also is being understood well as the meaning of positive conflicts, which is eventually being accepted and recognized by many of organizations. "In traditional hierarchical organizations, employees are supposed to inform their supervisors of conflicts and problems and abide by their decisions" (Alper et al, 2000). According to self-managing theory, employees are expected to deal with conflicts on their own. Plus, as macrocosms, organizations encourage each department to solve problems somewhat independently in order to guard against the emergence of conflicts interpersonally (Hackman, 1990; Thomas, 1992). Apparently, it is almost impossible to process organizational affairs solely. In reverse, interpersonal connection is frequently becoming the dominative organizational activity which is one of main parameters producing conflicts during the process of administrations. Of this idea which is completely different from the argument of self-managing proponents, interpersonal connection cannot be excluded from day-to-day administrations. Both managers and supervisors and employees should actively take part in interpersonal activities in working environments. Without doubts, more interactions may produce more different even conflicting ideas which probably engender conflicts among different departments. Comparing to think of how conflicts impact organizations, it is comparatively easier to understand that conflict is a universal issue attracting huge attentions not only from scholars but also from most of stakeholders.

\section{Conflict Effects: A Double-edged Sword}

Undoubtedly, conflicts within organizations cannot be starkly cleaned out and, in the meantime, organizational behaviors and results can be tremendously affected by somewhat internal conflicts which probably lead to either negative results or positive outcomes, which is a typically doubleedged sword for organizations. In this part, influences as a result of conflicts are divided into two polar folds based on the attribute of negative and of positive.

\subsection{Negativity}

\subsubsection{Harming decision-making in terms of money cost and time waste.}

Top administrative teams always pursue a perfect and productive outcome with a series of strategic decisions and quality administration methods (Amason, 1996, p. 123). Yet, each decision being made by decision makers needs to be processed thoroughly through a set of discussions which contain the majority of participants in the project. During this process, conflict could be one of confounding variables affecting the decision-making and the outcome of this project. There is a subtle relation between the organizational performance and conflicts inside. In order to get consensuses, based on the opinion by Schweiger et al (1992) that decision quality and consensus cannot be coexist peacefully, conflict is the crux of this process which may refer to different 
departments taking part and expressing divergent sometimes even conflicting voices. Decisionmaking could be wasteful in terms of time and resources including manpower and capitals. Conflict, in some sense, is one of parameters which may weaken the capability of teamwork (Schweiger et al, 1986. p. 67). Unquestionably, the purpose of decision-making is to implement some kinds of particular projects or schemes. Hence, the decision-making could be meaningless if the decision cannot be applied to specifically administrative process by organizations. There are two different fields when decision makers make up their minds which can be comprehended how conflicts make a difference in the process of making decisions and in the process of implementing the decision. If conflicts cannot be managed well when organizations make decisions and implement decisions, which could be a result of negative effects by conflicts in terms of low efficiency decision-making and of low equality decision-implementing as well as of huge costs on money and time.

\subsubsection{Worsening interpersonal relation bonds.}

The majority of organizations are chasing after harmonious working environments where employees can contribute with positive emotions. As an excellent case, Yahoo is being analyzed by theorists in terms of informal and relaxing work environments being provided for all participants. Employees in Yahoo are satisfied with the work surroundings and different sorts of advanced facilities on enhancing the quality of work. Meanwhile, work environments in Yahoo also have commendatory feedback from staff. Universally, all of huge organizations like Yahoo have comprehensive management methods to response to interpersonal conflicts emerging. Yet, conflict is inevitable in the majority of top administration teams as well (Amason, 1996, p. 127). As stated above, any discussions may cause interpersonal conflicts. Besides, personality is another crucial element which probably make a huge difference in daily communication, especially, casual communications in organizations, personality usually plays an active role in informal talking among colleagues. In comparison with formal decisions where most of participants pursue one target, casual communications may refer to more topics unrelated to job targets. That is easy to divide different casual colleague groups probably having less interactions with others. Several colleagues who have totally different personalities and values may face conflicts when certain opinions are totally contradictory. Interpersonal conflicts may cause negative effects for organizations. Importantly, creating harmonious environments closely relies on the relationship among colleagues. Thereof, managing conflicts among different colleagues with different personalities is crucial for organizations to set up harmonious working environments.

\subsubsection{Resulting in cut-throat competition.}

Plenty of conflicts researches show that many of conflicts from inside organizations are related to competition, which may lead to a range of approaches sabotaging and harming outcomes (Tjosvold, 2008, p. 19). Negative reputation for conflicts within organizations is contributed by unfair or unsound promotion systems. Pursuing a higher position is universally regarded as one of necessary paths to achieve career dreams. Usually, less opportunities incur extremely competitive surroundings among eligible employees. Particularly, certain of organizations with comparatively flimsy management capacities more easily to be pounced by so called cut-throat competition, which may lead to a range of troubles affecting daily administration and even worsen organizations reputation and break down the whole business strategies. The one of main reasons of forming cutthroat competition is negative competitions happening during the process of competing for the promotion.

\subsection{Positivity}

\subsubsection{Perfecting decision-making.}

This point mainly focuses on the outcome by well-managed conflicts, which differs from the first point we mentioned in the part of negative effects. Again, based on Tjosvold's statement (2008), conflicts within organizations may lead to constructive and essential ingredients for work groups. In teamwork, it is definitely impossible to avoid intersections with other departments 
regarding a project. Organizational administrators divide organizations into different working areas usually including accounting, human resources, marketing, etc. When conflicts happen, it often means that something really needs to be discussed more and deeply. In this regard, conflicts may play a positive role in driving organization constructions and in the meantime, more sparking ideas may be produced during the process of debating and discussing. Hence, comparing with conflicts negative sides, it also can contribute to decision-making. Especially, in some of hightechnological enterprises, discussion regarding different opinions is a better way of exchange ideas and gradually resulting in well-thought-results.

\subsubsection{Forestall corruptions.}

Conflicts may be encouraged in majority of democratic organizations and certain of big enterprises with complicated administration context. In China, according to the study by Tjosvold et al (2008), conflicts are rather useful for the teamwork and alliance at same time. Managing conflicts in western cultures is sometimes considered as a limitation to the individual, but in east context, particularly in China, since they are facing more rigid bureaucracy not only in authorities but also in state-owned enterprises (or SOEs). How to bypass corruption and reduce negative effects due to the bureaucracy among these big organizations become far crucial nowadays. Creating an open-mined surroundings for all staff who are eager to express own ideas is a useful way of curing this disease. More voices from different interests groups can lead to a more equal working environment for most of competitors. Also, it can make staff feel that they are treated on equal terms in case of the freedom and having opportunities of expressing ideas, which is crucial to development of interpersonal relationships when administration can really keep more transparent for the community. Plus, more importantly, if organizations can control well the process of conflicts, it would be one of effective ways of playing a role in monitoring. More communications among divergent departments can cause an environment with friendly competitions among staff and relatively apparent in terms of administration procedures.

\section{Necessities of Well-managed Conflicts}

\subsection{Costs on the Avoidance of Conflicts}

Conflict that exists in everywhere within organizations in some collectivist social context, like China, has been proved that it undermines performance and efficiency of organizations by field studies conducted by scholars. Some of field studies indicate that trying to avoid conflicts in diverse organizational settings is seldom useful (Tjosvold, 2008, p. 23). Several reasons could be applicable to explain why avoiding conflicts is seldom useful. Firstly, in order to get away from conflicts within organizations, the coordinators need to classify instantiation of conflicts in different departments that could be a complex procedure and probably cost a lot not only on capital but on other invisible sides. Secondly, avoiding conflicts could cause more other interpersonal clashes, which may be kinds of unstably confounding parameters probably affecting the harmonious of work environment. Last but not the least, based on the second possibly harmful parameter, if administrators cannot handle issues well, the result of avoiding conflicts either produce new interpersonal conflicts or harm positive influence brought about by certain of positive conflicts. For example, the decreasing of awareness of positive competition among employees, which is potential parameter harming the work efficiency. In a word, it sounds like impossible to try to avoid conflicts in any possible ways under the modern organizational structure. The avoidance of conflicts not only is infeasible but also breach basic rule of organizational operation, which probably bring about huge costs to organizations.

\subsection{Benefits of Well-managed Conflicts}

As shown by arguments given above, a number of benefits could be produced when organizations make use of all kinds of approaches well to manage conflicts. Except advantages above, some of other benefits are also proved that well-managed conflicts are definitely necessary. 
For instance, the most crucially, the majority of well-thought ideas need a comparatively conflicting environment to be up. Particularly, what is quite crucial for high-technology enterprises is an actively conflicting environment for discussion. Less conversation happening among divergent departments, less productive outcomes can be produced. In addition, a friendly competitive work environment is a key of improving job efficiency. A good model of well- managed conflicts can help to build up this type of ideal work environment. All of participants may become more innovative and creative when they work in such organizations.

\section{The Strategies to Achieve Well-managed Conflicts}

According to Thomas et al (1974), there is a classical taxonomy (see figure. 1) that discourse five different approaches to handle conflicts. The first dimension in the taxonomy is avoidance that is an approach which bring about low cooperation among colleagues and refuse to express freely. In the meantime, it could be an effective way to cool employees down when the emotions are high. The second one included in the version of taxonomy is competition, which could harm interpersonal relations if competing comes out frequently. Yet, at same time, using competing appropriately to handle conflicts in organizations could respond promptly to certain emergencies happening. Next strategy which should be encouraged to apply to solve practical conflict issues is collaboration. Even though trying to find out ways to collaborating could lead to time-consuming, it is still recognized by administrators as one of the most effective methods to solve the conflicts in organizations due to the biggest advantages of concerning and satisfying interests of all participants. The fourth one in the portfolio of conflict-handling ways is accommodation, which highlights highly frequent cooperation among colleagues for getting to ultimate targets. Organizations train colleagues how to concern with counterparts and cultivate harmoniously collaborative surroundings in order to enhance the efficiency. Lastly, compromising should play an active role in handling conflicts. What is worthy of pointing out is that compromising does not mean integrating. Compromising emphasizes on how to balance and coordinate the relationship between competition and cooperation.

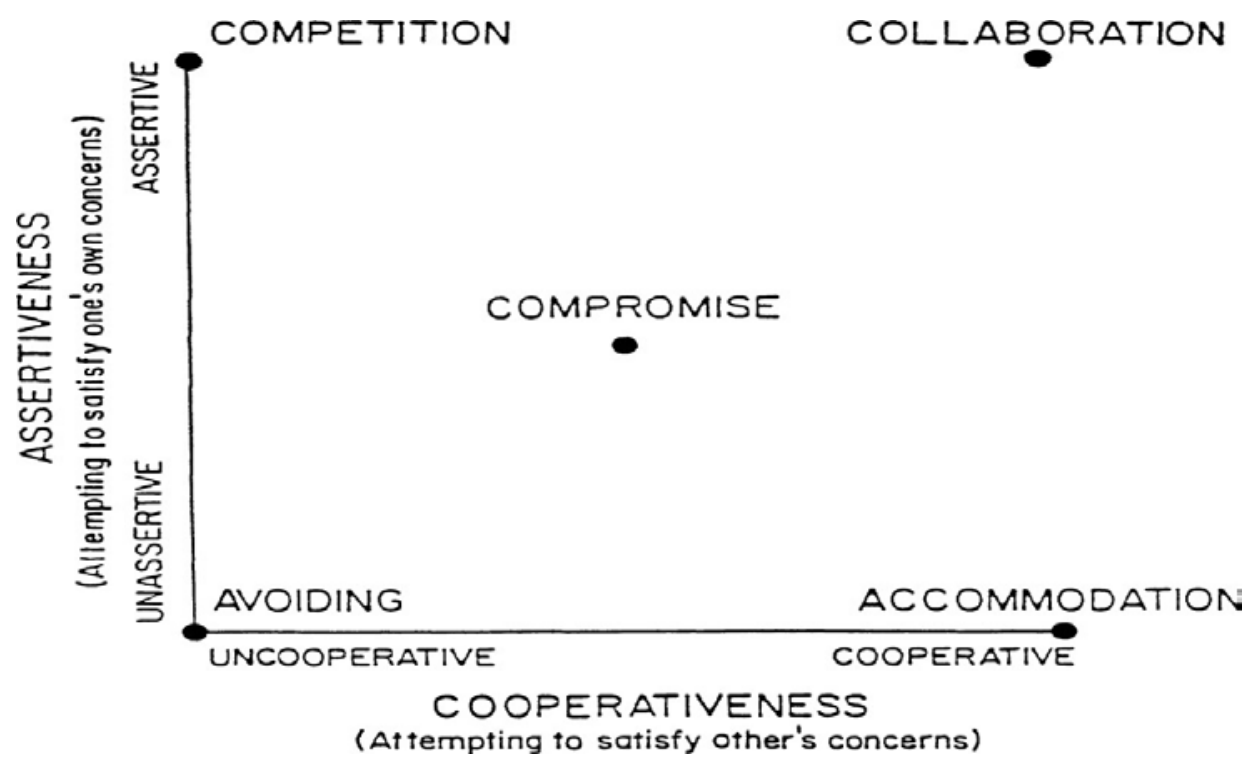

Fig. 1. The two-dimensional coordinate of taxonomy of conflicts managing modes.

Source: Thomas, K. W., \& Kilmann, R. H. (1974). Thomas-Kilmann Conflict Mode Instrument, Xicom, Inc., Tuxedo, NY.

No matter what specific strategy organizations adapt to handle conflicts, manpower should be considered deliberately. Training employees how to cooperate and compromise as well as communication is one of crucial tasks for administrators who are in charge of coordinating the different interests groups. Plus, when organizations handle conflict issues, administrators should use of different strategies to solve different kinds of conflicts coming out in different situations. 


\section{Conclusion}

To summarize, conflicts are everywhere in diverse organizational settings which could be influenced a lot by how organizations response to conflicts existing in the process of administration. Productive work outcomes and high efficient employees are one of results of well-managed conflicts, which can starkly reflect whether organizations are capable to handle conflicts well. As to the mentioned above, conflict is a double-edged sword that could harm the benefits of organizations, at same time it probably bring about satisfactions for all of stakeholders in organizations as long as organizations figure out the proper methods. Based on the two-dimensional taxonomy, organizations should consider how to adapt strategies to manage conflicts in order to get to ultimate organizational targets. In addition, crucially, training a quality administrative team plays a tremendously crucial role in pursuing perfection of managing conflicts and of business operation as well as of organizational values.

\section{References}

[1] Alper, S., Law, K. S., \& Tjosvold, D. (2000). Conflict management, efficacy and performance in self-managing work teams. Personal Psychology, 53, 625-642.

[2] Amason, A. C. (1996). Distinguishing the effects of functional and dysfunctional conflict on strategic decision making: Resolving a paradox for top management teams. Academy of Management Journal, 39, 123-148.

[3] Hackman, J. R. (1990). Groups that (work and those that don't). San Francisco: Jossey-Bass. Myers, L. L., \& Lawson, R. S. (2005). Preparing students for early work conflicts. Business Communication Quarterly, 68, 306-317.

[4] Neck, C. P. \& Manz, C. C. (1994). From groupthink to team think: Toward the creation of constructive thought patterns in self-managing work teams. Human Relations, 47, 929- 952.

[5] Sims, H. P. Jr. (1995). Challenges to implementing self-managing teams - Part 2. Journal for Quality \& Participation, 18, 24-31.

[6] Schweiger, D. M., Sandberg, W. R., \& Ragan, J. W. (1986). Group approaches for improving strategic decision making: A comparative analysis of dialectical inquiry, devil's advocacy, and consensus. Academy of Management Journal, 29, 51-71.

[7] Schweiger, D. M., Chatterjee, s., Lubatkin, M. H., \& Webber, Y. (1992). Culture differences and shareholder value in related mergers: Linking equity and human capital. Strategic Management Journal, 13, 319-334.

[8] Thomas, K. W. (1992). Conflict and negotiation processes in organizations. In M. D. Dunnette \& L. M. Hough (eds). Handbook of Industrial and Organizational Psychology, 3, 651-717.

[9] Tjosvold, D. (2008). The conflict-positive organization: it depends upon us. Journal of Organizational Behavior, 29, 19-28. 